\title{
Editorial
}

\section{US Still Off-key with Comparable Profits Method}

Toshiaki Katsushima, Deloitte Touche Tohmatsu, Tokyo

Reviewing recent reports about transfer pricing settlements between major Japanese multinationals and the IRS - and the large number of major cases which remain outstanding one can restate the need for harmony in establishing fundamental international tax principles. Clearly, when one country adopts rules which are inconsistent with internationally accepted standards, multinational businesses are faced with a significant risk of double taxation.

A recent example of such a problem is the adoption by the IRS of the Comparable Profits Method (or CPM) as a primary method in the temporary transfer pricing regulations issued a year ago. Even more troubling is the possibility that, after a year of analysis, comments and hearings, there is still risk that in practice CPM could become the primary method in transfer pricing audits in the United States.

From a Japanese tax perspective, CPM has a number of flaws. For example, if a company's operating profits deviate from certain easily-compiled base statistics, the IRS could use CPM to attribute the deviation to improper transfer pricing even though operating profits may include the results of transactions with unrelated parties. The IRS CPM analysis would also ignore the fact that in actual business transactions a number of factors besides transfer pricing contribute to low profitability. For example, in its CPM analysis the IRS could ignore the effect of the company's management style and policies and the quality and experience of the management team.

The apparent flaws in CPM may be further exacerbated by an overuse of CPM in the field. That is, IRS agents are likely to be strongly influenced by the presumption in the regulations that CPM 'ordinarily' will provide an 'accurate' measure of an arm's length result.' After the hearing in Washington in August 1993, businesses in Japan were interested to learn that the IRS may reconsider that particular aspect of the temporary regulations. However, there is still concern that the regulations may have given other 'structural' advantages to CPM.

One example is the apparent ease with which CPM might be applied, since the standards of comparability for applying CPM are less restrictive than those for the other methods. It is certainly difficult to anticipate a speedy resolution at Competent Authority for an IRS adjustment which is based on an unusual methodology and using comparables which are at best 'broadly similar' and which admit 'significant product diversity and some functional diversity'.

One of the major improvements in the temporary regulations is the abandonment of the strict priority of methods. The taxpayer is now required to analyse all available methods and apply the 'best method'. ${ }^{3}$ The 'best method rule' has been viewed by the international business community as a valuable contribution to the transfer pricing debate. Given the significance of the 'best method' concept, it is recommended that, as the IRS considers the content of final regulations, it ensures that the scales would have not been tipped in favor of CPM. An overuse of CPM in the field would violate the best method rule and, in so doing, the conceptual framework of the regulations.

Although the regulations purport to have removed the priority of methods, it seems as if some methods remain more equal than others. For example, the use of an 'other method'

\footnotetext{
${ }^{\prime}$ Temp. Reg. section 1.482-5T(a).

2 Temp. Reg. section 1.482-5T(c)(1) and -5T(d)(2).

3 The determination of the best method is to be based on a number of factors including the reliability of the data, the degree of comparability with third-party transactions and the adjustments required to apply each method. Temp. Reg. section 1.482-1T(b)(2)(iii)(A).
} 
carries a number of procedural disadvantages and burdens for the taxpayer. ${ }^{4}$ And notwithstanding compliance with extensive special procedures, a taxpayer using an 'other method' remains exposed in satisfying the 'reasonable belief' requirement to avoid the section 6662 penalties.

The restrictions on using an 'other method' are particularly troublesome when the taxpayer's method has been accepted in his home country and by other tax jurisdictions. To penalize the taxpayer for consistently applying the method which provides the most accurate measure may be a violation of the best method rule. If an 'other method' is the best method, the taxpayer should be free to adopt such method without suffering incremental procedural risks and burdens.

The debate surrounding North American Free Trade Agreement (NAFTA), the AsiaPacific Economic Cooperation (APEC) forum and the GATT Uruguay Round has focussed the international business community on the disadvantages of impediments to trade. Tax legislation obviously plays an important part in this process. It seems quite clear that when one tax authority adopts positions which can not be reconciled with the accepted international rules, the system itself, not to mention the burden of double taxation, becomes an impediment.

If the final regulations under section 482 encourage CPM to be overused in the field even when it is not the best method, such a policy by the IRS can only perpetuate the high level of transfer pricing disputes. And because CPM is not generally accepted as an international standard, unusual methodologies will continue to hamper the resolution of competent authority cases and lead to an increase in double taxation. If multinational corporations must build the possibility of significant double taxation into their business and investment plans, the system has failed.

Given that CPM is a new method which has not been tested in practice, it is recommended that CPM not be included in final regulations until the new method has been thoroughly studied by OECD and there is a general understanding concerning the application of the method and the database to be employed by the IRS in establishing the benchmarks. Until there is international consensus concerning CPM, it should not be viewed as one of the primary methods and should be applied only in limited circumstances.

\footnotetext{
${ }^{4}$ The regulations require the taxpayer to determine the best method from among a variety of methods including CUP, resale price, cost-plus and CPM. If these methods can not be applied then an alternative - a so-called 'other method' - should be used. Temp. Reg. section 1.482-3T(a) and -3T(e)(1). A taxpayer using an 'other method' must make a special disclosure on its tax return, prepare extensive contemporaneous supporting documentation supporting the specific analysis, and upon request furnish the documentation of the IRS within 30 days. Temp. Reg. section $1.482-3 \mathrm{~T}(\mathrm{e})(2)$.

${ }^{5}$ Temp. Reg. section 1.482-3T(e)(3).
} 